\title{
Crisis en las entidades de crédito españolas: Un estudio mediante análisis discriminante*
}

\author{
DAVId REDONDO BALlesteros a , José MigUel RodríGUEZ FERNÁNDEZ ${ }^{\text {a }}$ \\ a Universidad de Valladolid, Facultad de CC.EE., Avda. Valle de Esgueva, 6, 47011 Valladolid, \\ España.E-mail: dareba@hotmail.com,jmrodrig@eco.uva.es
}

\begin{abstract}
RESUMEN
El objetivo de este trabajo es presentar un modelo de clasificación de entidades bancarias estimado mediante la técnica del análisis discriminante lineal multivariante, precedido de un breve recorrido sobre la evolución de la reciente crisis bancaria en España. Se utiliza una muestra de estimación y otra de validación, cada una de ellas con instituciones de depósito españolas en dos circunstancias distintas: solventes y con dificultades financieras. Los datos corresponden a los años 2008 y 2009, un ejercicio previo a las respectivas situaciones de fracaso. Los resultados empíricos alcanzados son estadísticamente significativos, confirman algunas conclusiones de estudios efectuados en épocas anteriores y parecen útiles para diseñar sistemas de alerta temprana en el sector bancario.
\end{abstract}

Palabras clave: Modelos de alerta temprana, análisis discriminante, sistema bancario español, crisis financiera.

\section{Crisis in Spanish Credit Institutions: Discriminant Analysis Application}

\begin{abstract}
The aim of this paper is to present an estimated model for banking classification applying multivariate linear discriminant analysis, preceded by a brief review of recent Spanish crisis. An estimation sample and a validation sample are used, each of them with Spanish depository institutions solvent and another financial distressed. The data refers to the years 2008 and 2009, a prior fiscal year to the respective situations of failure. The empirical results achieved are statistically significant. They confirm some of the conclusions from previous studies and seem to be useful to design early-warning systems in the banking sector.
\end{abstract}

Keywords: Early-Warning System Models, Discriminant Analysis, Spanish Banks, Financial Crisis.

Clasificación JEL: G21, G28, G33, G34

\footnotetext{
* Los autores agradecen los útiles comentarios y sugerencias de dos evaluadores anónimos. Además, José Miguel Rodríguez Fernández expresa su reconocimiento por la ayuda financiera recibida del Ministerio español de Ciencia e Innovación (proyecto ECO2011-26171).
}

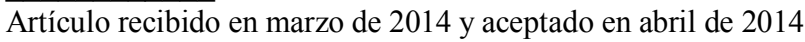

Artículo disponible en versión electrónica en la página www.revista-eea.net, ref. ə-32214 


\section{INTRODUCCIÓN}

La reciente crisis en los mercados financieros y sus consecuencias en la economía real han atraído la atención, tanto de académicos como de profesionales, sobre los modelos empíricos de predicción de insolvencias bancarias. Estudios previos han sugerido las ventajas de utilizar sistemas de alerta temprana, preventiva, para pronosticar las crisis bancarias. Por esta razón, dichos sistemas se han ido difundiendo en el ámbito académico, en el sector financiero y, muy en especial, entre los reguladores bancarios, sobre todo en los Estados Unidos.

El objetivo del presente trabajo es identificar los principales indicadores económico-financieros microeconómicos -individuales- y las variables macroeconómicas que pueden ayudar a explicar la situación de dificultades financieras en instituciones bancarias, permitiendo reconocer futuras entidades en riesgo de fracaso. Para ello, se estudia lo acontecido recientemente a ese respecto en el caso español, lo cual conduce a estimar una función discriminante lineal. Aquí se entiende por instituciones bancarias las que reciben depósitos del público o, dicho de otro modo, aquellas entidades de crédito de carácter monetario, con independencia de su denominación formal en términos legales. Se trata de determinar dónde cabe encontrar algunas claves a la hora de predecir aquellos operadores financieros que pudieran mostrar ulteriormente una mayor debilidad. Esto puede ayudar a la articulación de políticas de prevención de crisis ante eventuales episodios de inestabilidad financiera.

La importancia de este campo de investigación se ha puesto claramente de manifiesto durante las últimas dos décadas, cuando muchos países, tanto desarrollados como en desarrollo, han experimentado insolvencias bancarias de algún tipo. De hecho, según estimaciones sobre los costes totales promedio de las reestructuraciones bancarias posteriores a las correspondientes crisis, parece que, con carácter general, ya en la pasada década de los noventa han podido representar entre el $6 \%$ y el $10 \%$ del producto interior bruto (PIB) del respectivo país (Hutchison y McDill, 1999). Obviamente, si el fracaso de una institución financiera se presentara como un hecho predecible, el coste de su insolvencia podría, en el peor de los casos, reducirse considerablemente, de no ser factible eliminarla por completo.

Mientras países como Reino Unido, Francia, Alemania o Dinamarca iniciaban en los años 2008 ó 2009 la recapitalización de sus bancos, en España la opinión generalizada era en esos momentos que nuestro sistema financiero gozaba de gran solidez, su restructuración resultaba innecesaria y una posible recapitalización futura no precisaría de un elevado monto de recursos. Sin embargo, años después comprobamos que esas predicciones han sido erróneas. Cuando por fin se tomaron las iniciativas pertinente, ya era tarde, multiplicándose cuantiosamente tanto las consecuencias de la crisis financiera como los fondos requeridos y movilizados para hacerla frente. No es de extrañar que nu- 
merosos informes de instituciones internacionales, como, por ejemplo el Fondo Monetario Internacional, hayan concluido que uno de los mayores errores de la reestructuración efectuada en el sector bancario español ha sido iniciarla con lentitud, por subestimar en un principio los problemas. Los síntomas de riesgo existían desde 2008.

Para dar respuesta a los objetivos planteados, el trabajo consta, además de la presente introducción, de otros cinco epígrafes principales. Así, el epígrafe segundo presenta la transformación del sistema financiero español durante los últimos años, centrando nuestra atención sobre el sector de las cajas de ahorros, máximo exponente de los procesos de reestructuración de dicho sistema. En el epígrafe tercero se realiza un recorrido sintético por la literatura previa existente en cuanto a modelos de alerta temprana que toman el sector financiero como eje central. El epígrafe cuarto proporciona una visión general del diseño de la investigación empírica, incluyendo fuentes de datos, muestra utilizada y metodología de estadística multivariante aplicada. En el epígrafe quinto se resumirán los principales resultados alcanzados mediante la aplicación de esa metodología previamente explicada. El trabajo termina con la presentación de algunas reflexiones finales y las principales conclusiones del mismo.

\section{REESTRUCTURACIÓN DEL SISTEMA BANCARIO ESPAÑOL}

La actual crisis española tiene un componente propio, originado durante la fase de expansión que siguió a la coyuntura adversa de los años 1992 y 1993 y que se extendió hasta el estallido de la actual crisis en el verano de 2008. Durante ese periodo de expansión, se fueron acumulando en nuestro país graves desequilibrios macroeconómicos y financieros.

En efecto, como consecuencia de los síntomas de fortaleza que presentaba la economía española, sus hogares se fueron endeudando a un ritmo cada vez mayor. A lo largo de los quince años aludidos, la inversión crediticia del conjunto de las instituciones bancarias en el sector privado residente aumentó a un ritmo medio anual del 15 por ciento, velocidad que se aceleró en la parte final del periodo, llegando a niveles medios del $23 \%$ entre 2004 y 2007 . De tal manera que la deuda bruta de los hogares y sociedades no financieras pasó desde el 107 por ciento del PIB en 2000 al 201 por ciento a finales de 2011 El principal impulsor de este crecimiento se encuentra en el crédito total destinado al sector de la construcción y actividad inmobiliaria, alimentado por la paridad fija e irrevocable establecida entre euro y peseta, el consiguiente más fácil acceso a los mercados internacionales de refinanciación al por mayor, unos bajos tipos de interés y la creciente burbuja en la valoración de activos inmobiliarios. De esta forma, en tan sólo quince años los créditos relacionados con la construcción, compra o rehabilitación de vivienda y servicios inmobiliarios se multiplicaron 
por más de doce, desde 88.500 millones a 1,07 billones de euros, superando en el año 2007 el $60 \%$ de la financiación al sector privado residente. Las cajas de ahorros fueron las entidades que más concentraron sus créditos en ese ámbito de la construcción, compra o rehabilitación de vivienda y actividad inmobiliaria: mientras que, al finalizar el año 2007, en los bancos propiamente dichos el nivel de exposición se situó en torno al 50\% del total de créditos concedidos al sector privado residente, en el caso de las cajas de ahorros esos créditos llegaron a representar más del 70\% del total (Banco de España, 2012a; Rallo, 2008).

Este formidable endeudamiento con tal finalidad por parte de los agentes privados con fondos concedidos por las entidades de crédito españolas propició, además, una dependencia excesiva de estas últimas respecto a los mercados extranjeros de financiación mayorista e interbancaria. Ello situó a esas instituciones y, por extensión, al conjunto de la economía española en una posición de latente vulnerabilidad frente a eventuales fenómenos de inestabilidad financiera mundial. Lo vinieron a confirmar los hechos, tras la crisis financiera iniciada a mediados de 2007 en Estados Unidos y desde allí contagiada al resto de los sistemas financieros.

Una vez que en España se hace patente la crisis internacional, comenzó la aplicación de determinadas medidas. Inicialmente, se crearon el Fondo de Adquisición de Activos Financieros (FAAF), dedicado a administrar y gestionar la compra de activos de las entidades de crédito para dotarlas de liquidez, y el Fondo de Reestructuración Ordenada Bancaria (FROB), con objeto de dirigir los procesos de reestructuración y resolución de problemas en esas entidades. Como consecuencia, las primeras inyecciones de capital público al sector bancario tuvieron lugar en el año 2009, al hilo de las intervenciones por parte del Banco de España en Cajasur y Caja Castilla-La Mancha para garantizar la solvencia de estas organizaciones. También entonces tuvieron lugar los primeros procesos de fusión, a raíz de la absorción por parte de BBVA, Banco Popular Español y Deutsche Bank de algunas de sus propias entidades filiales.

Ante la incertidumbre existente, en julio de 2010 verá la luz el Real Decretoley $11 / 2010$, con el fin de solventar las dos principales limitaciones detectadas en las cajas de ahorros de nuestro país: sus problemas de gobierno corporativo y su incapacidad o imposibilidad para captar capital (propio) en los mercados financieros. Entre los hitos más relevantes acontecidos durante este año en el sector, destacan los siguientes: a) el nacimiento de Banca Cívica, Banco Mare Nostrum y Grupo Banco Financiero y de Ahorros (matriz de Bankia), a partir de diferentes sistemas institucionales de protección $(\mathrm{SIP})^{1}$; b) las fusiones de Uni-

\footnotetext{
${ }^{1}$ Se entiende por sistema institucional de protección (SIP) un proceso de agrupación de entidades bajo una estructura de gestión común, donde se mantienen las marcas comerciales independientes, con sus órganos de gobierno propios. El proceso de agrupación de varias entidades bajo un SIP ha sido conocido periodísticamente como "fusión fría".
} 
caja con Caja Jaén, de Caja España con Caja Duero, y Caixa Galicia con Caixanova; y c) las fusiones por absorción de Caja Guadalajara por Cajasol y Caixa Girona por La Caixa. También en 2010 se califican a Cajamar y al Grupo Cooperativo de Cajas Rurales del Mediterráneo como grupos consolidables ${ }^{2}$.

Durante el año 2011, siguieron desarrollándose nuevas operaciones de reestructuración. Muchas de ellas como consecuencia directa del Real Decreto-ley $2 / 2011$. Éste elevó los requerimientos de capital, estableciéndose al respecto un nuevo coeficiente mínimo de core capital (o capital principal) del 8 por ciento sobre los activos ponderados por riesgo, siendo el 10 por ciento para aquellas entidades muy dependientes de los mercados mayoristas de fondos, caso de las cajas de ahorros.

Inicialmente, diez entidades -ocho cajas de ahorros y dos bancos- no cumplían los nuevos requerimientos de capital exigidos; y estaba previsto que, de no poder solventar esa circunstancia mediante medios propios antes del 30 de septiembre de 2011, sería el FROB quien completase la recapitalización exigida. En el caso de esas ocho cajas en tal situación, la solución generalizada fue el traspaso de su negocio financiero a nuevos bancos, los cuales por su forma jurídica podían intentar captar capital privado en los mercados financieros, a la vez que esto implicaba pasar a una forma de organización en que las cajas de ahorros realizaban su actividad financiera de manera indirecta. Más cajas de ahorros siguieron finalmente este camino, de modo que al término de 2011 eran once las que se orientaron en esa dirección, dando lugar al denominado proceso de bancarización de las mismas.

Mientras los procesos de integración y recapitalización avanzaban, persistían los problemas de confianza en el sector financiero español y de restricción de crédito a su economía. Ante esta realidad, en el año 2012 se articularon una serie de nuevas medidas para acelerar los procesos de reestructuración, sanear los balances y reforzar los niveles de solvencia de las entidades de crédito españolas, con la ayuda de la Unión Europea.

Una de estas medidas es la Ley 9/2012, de reestructuración y resolución de entidades de crédito, mediante la cual se creó la Sociedad de Gestión de Activos Procedentes de la Reestructuración Bancaria (Sareb), con el fin de administrar determinados activos procedentes de las entidades nacionalizadas y/o receptoras de ayudas públicas. En 2012, dicha sociedad adquirió los activos de las cuatro entidades controladas accionarialmente por el FROB -Bankia, Catalunya Bank, Novagalicia y Banco de Valencia-, lo que implicó un desembolso de unos 40.000 millones de euros (Banco de España, 2012b). Y se superaron los 50.000

\footnotetext{
${ }^{2}$ Se considera "grupo consolidable" de entidades de crédito aquel conjunto de instituciones en el cual una de ellas tiene o puede tener, de manera directa o indirecta, el control sobre otras, siendo siempre la entidad que domina una entidad de crédito.
} 
millones de euros tras adquirir los activos de nuevas entidades con necesidades de capital y que hubieron de acudir a ayudas públicas: Liberbank, BMN, Ceiss y Caja 3.

Adicionalmente, la mencionada Ley recogía la posibilidad de transformación de las cajas de ahorros en fundaciones de carácter especial ${ }^{3}$. A finales del año 2012, ocho cajas de ahorros ya se habían transformado en fundaciones de carácter especial: las siete que participaron en la creación de Bankia y Caixa Catalunya. A ellas se sumaron otras seis en los primeros meses de 2013: Caja Mediterráneo, Caja Navarra, Cajasol, Caja General de Canarias, Caja Burgos y Unnim.

En el año 2013, se materializan o se inician nuevos procesos de fusión: Caja 3 es absorbida por Ibercaja Banco, pasando a formar parte del mismo; Banco CEISS se orienta a la integración con Unicaja; y Banco Etcheverría compra a Novagalicia, pasando ambas posteriormente a ser filiales del banco venezolano Banesco. Además, nuevos bancos y cooperativas de crédito se han ido integrando dentro de sus matrices o constituyendo grupos consolidables, respectivamente.

Por último, con la Ley 26/2013, de 27 de diciembre, de cajas de ahorros y fundaciones bancarias, se acelera la extinción del sistema existente de cajas de ahorros. El grueso de ese sector se transformará en fundaciones bancarias antes de finales de 2014, siendo previsible que sólo Caixa Pollensa y Caixa Ontinyent continuarán con su status tradicional.

Como resultado de todos estos acontecimientos, del total de las 192 entidades de depósito que operaban en España a comienzos de 2009 -sumando cajas de ahorros, bancos y cooperativas de crédito-, 88 han participado en alguno de los procesos de fusión y creación de nuevas entidades; y más de medio centenar ha pasado a formar parte de algún grupo financiero. El sector bancario actualmente cuenta con 123 entidades, repartiéndose casi al 50 por ciento entre bancos y cooperativas de crédito, según la información disponible en diciembre 2013.

Un resumen, entre 2009 y 2013, del proceso de reestructuración hasta aquí apuntado queda reflejado en la Tabla 1.

\footnotetext{
${ }^{3}$ Aquellas cajas de ahorros que perdieran el control, o tuvieran una participación inferior al 25\% de los derechos de voto de la entidad de crédito a través de la que ejercen su actividad financiera, pasarían a transformarse en fundación de carácter especial, orientando su actividad a la atención y desarrollo de la Obra Social y a la adecuada gestión de su participación en la entidad de crédito.
} 
Tabla 1

Restructuración de las principales entidades bancarias españolas (2009-2013)

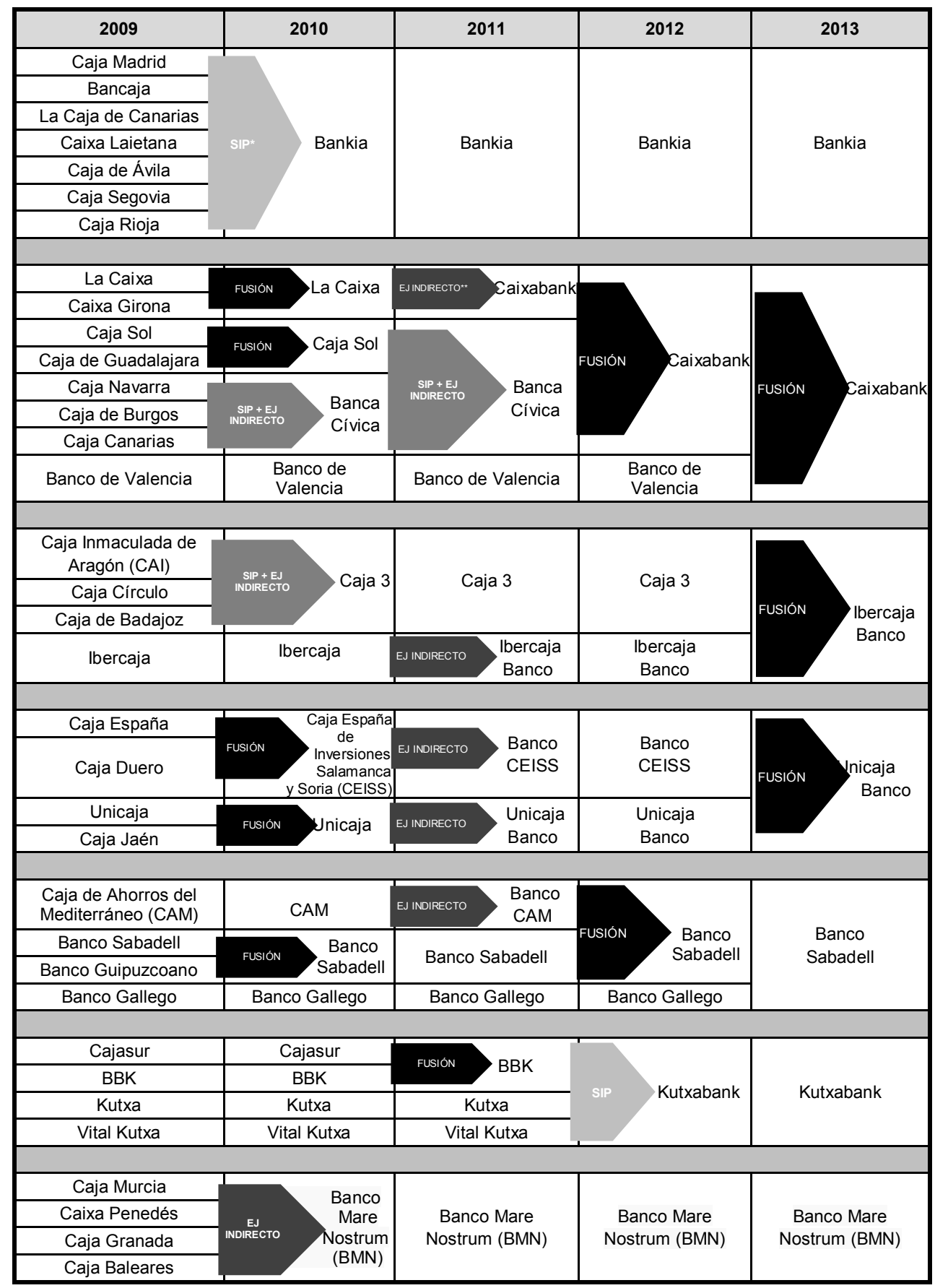


Tabla 1 (continuación)

Restructuración de las principales entidades bancarias españolas (2009-2013)

\begin{tabular}{|c|c|c|c|c|}
\hline 2009 & 2010 & 2011 & 2012 & 2013 \\
\hline Caixa Sabadell & \multirow{3}{*}{ FUSIÓN $>$ Unnim } & \multirow{3}{*}{ Unnim Banc } & \multirow{4}{*}{ FUSIÓN } & \multirow{4}{*}{ BBVA } \\
\hline Caixa Terrassa & & & & \\
\hline Caixa Manlleu & & & & \\
\hline BBVA & BBVA & BBVA & & \\
\hline Caixa Catalunya & & \multirow{3}{*}{$\begin{array}{l}\text { Catalunya } \\
\text { Banc }\end{array}$} & \multirow{3}{*}{$\begin{array}{l}\text { Catalunya } \\
\text { Banc }\end{array}$} & \multirow{3}{*}{$\begin{array}{l}\text { Catalunya } \\
\text { Banc }\end{array}$} \\
\hline Caixa Tarragona & $\begin{array}{l}\text { atalunya } \\
\text { Caixa }\end{array}$ & & & \\
\hline Caixa Manresa & & & & \\
\hline Caixa Galicia & \multirow{2}{*}{ FUSIÓN } & \multirow{2}{*}{$\begin{array}{l}\text { EJ INDIRECTO } \\
\text { Banco }\end{array}$} & \multirow{2}{*}{$\begin{array}{c}\text { Novagalicia } \\
\text { Banco }\end{array}$} & \multirow{3}{*}{ FUSIÓN } \\
\hline Caixanova & & & & \\
\hline Banco Etcheverría & $\begin{array}{c}\text { Banco } \\
\text { Etcheverría }\end{array}$ & Banco Etcheverría & Banco Etcheverría & \\
\hline \multirow{2}{*}{$\begin{array}{l}\begin{array}{l}\text { Caja Castilla-La } \\
\text { Mancha (CCM) }\end{array} \\
\text { Cajastur }\end{array}$} & \multirow{2}{*}{ FUsIón Sajastur } & \multirow{4}{*}{ SIP Liberbank } & \multirow{4}{*}{ Liberbank } & \multirow{4}{*}{ Liberbank } \\
\hline & & & & \\
\hline Caja de Extremadura & $\begin{array}{c}\text { Caja de } \\
\text { Extremadura }\end{array}$ & & & \\
\hline Caja Cantabria & Caja Cantabria & & & \\
\hline Caixa Ontinyent & Caixa Ontinyent & Caixa Ontinyent & Caixa Ontinyent & Caixa Ontinyent \\
\hline $\begin{array}{c}\text { Colonya Caixa } \\
\text { Pollença }\end{array}$ & $\begin{array}{c}\text { ColonyaCaixa } \\
\text { Pollença }\end{array}$ & $\begin{array}{c}\text { ColonyaCaixa } \\
\text { Pollença }\end{array}$ & $\begin{array}{c}\text { Colonya Caixa } \\
\text { Pollença }\end{array}$ & $\begin{array}{l}\text { Colonya Caixa } \\
\text { Pollença }\end{array}$ \\
\hline Banca March & Banca March & Banca March & Banca March & Banca March \\
\hline Banco Popular & Banco Popular & Banco Popular & \multirow{2}{*}{\begin{tabular}{l|l} 
Busión & Banco \\
Popular
\end{tabular}} & \multirow{2}{*}{ Banco Popular } \\
\hline Banco Pastor & Banco Pastor & Banco Pastor & & \\
\hline Banco Santander & Banco Santander & Banco Santander & Banco Santander & Banco Santander \\
\hline Bankinter & Bankinter & Bankinter & Bankinter & Bankinter \\
\hline Grupo Cajamar & & & & \\
\hline Caixa Rural de Balears & GRUPO & & & \\
\hline Caja Rural Castellón & & GRUPO & & \\
\hline Caja Rural de Canarias & $\begin{array}{l}\text { Caja Rural de } \\
\text { Canarias }\end{array}$ & & Grupo & \\
\hline Grupo CRM & Grupo & & $\begin{array}{l}\text { Cajas } \\
\text { Rurales }\end{array}$ & $\begin{array}{l}\text { Rurupo Uajas } \\
\text { Runidas }\end{array}$ \\
\hline Caja Rural de Villar & GRUPO & & Unidas & \\
\hline $\begin{array}{c}\text { Caixa Rural de la Vall } \\
\text { d'Uixó }\end{array}$ & $\begin{array}{l}\text { C. R. de la Vall } \\
\text { d'Uixó }\end{array}$ & $\begin{array}{l}\text { Grupo } \\
\text { CRM }\end{array}$ & & \\
\hline $\begin{array}{c}\text { Caja Rural Católico } \\
\text { Agraria }\end{array}$ & $\begin{array}{l}\text { C. R. Católico } \\
\text { Agraria }\end{array}$ & & & \\
\hline
\end{tabular}


Tabla 1 (continuación)

Restructuración de las principales entidades bancarias españolas (2009-2013)

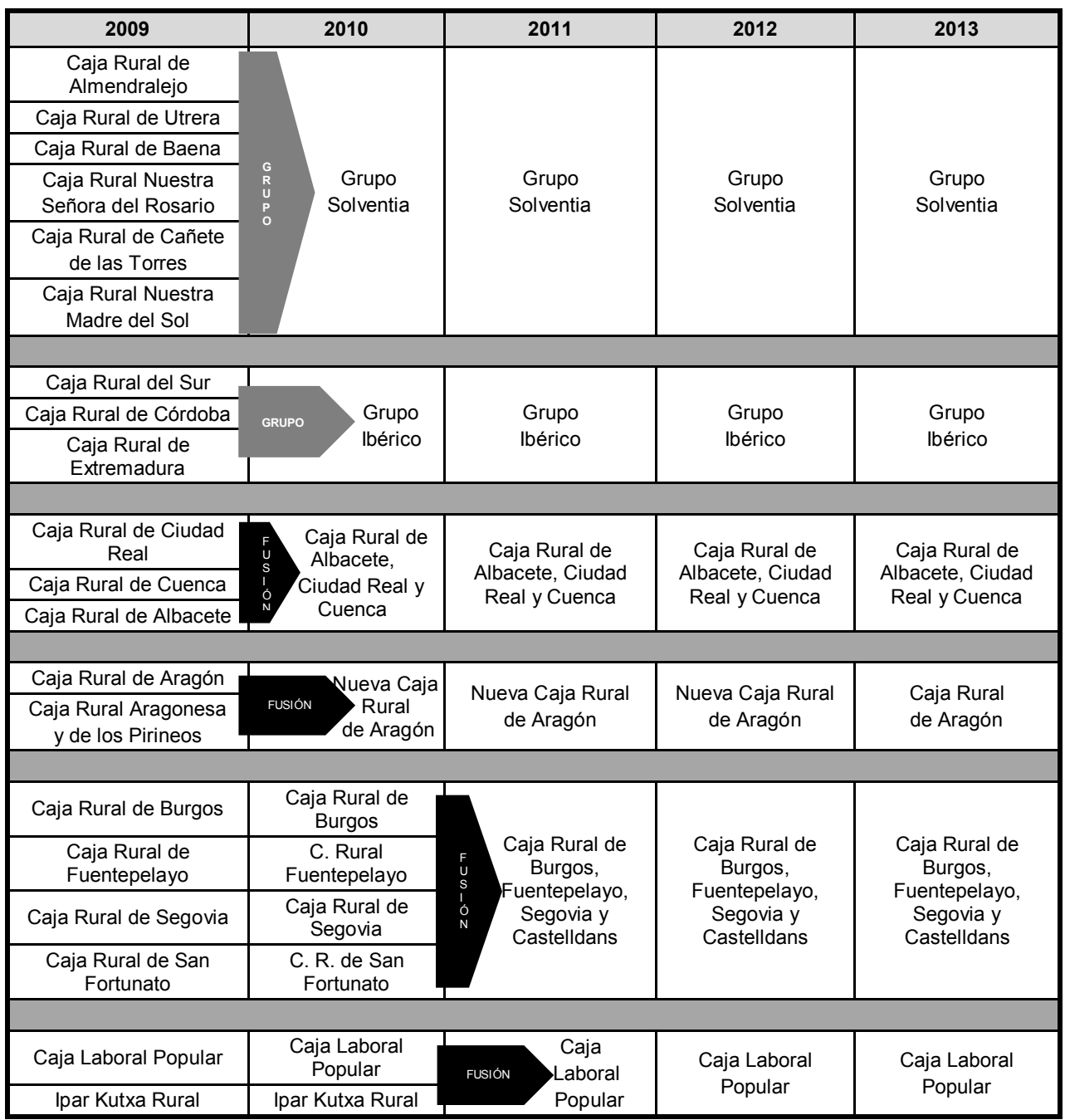

* SIP: Sistema institucional de protección.

* EJ INDIRECTO: Ejercicio indirecto de la actividad financiera.

Fuente: Elaboración propia a partir de los datos proporcionados por Confederación Españolas de Cajas de Ahorros (CECA), Asociación Española de Banca (AEB), Unión Nacional de Cooperativas de Crédito (UNCC) y Banco de España.

\section{MODELOS DE ALERTA TEMPRANA: LITERATURA PREVIA}

Desde hace más de treinta y cinco años, diversos estudios empíricos vienen presentando estimaciones de modelos de predicción del fracaso bancario, mo- 
delos que pueden ser útiles para facilitar una alerta temprana acerca de posibles problemas en alguna entidad. En esencia, el objetivo es tratar de identificar si existe relación entre las dificultades financieras de las instituciones de crédito y su perfil económico, financiero, bursátil, de gobierno corporativo y/o la coyuntura macroeconómica en períodos previos, apoyándose en métodos estadísticos o econométricos (Scapens et al., 1981).

Una técnica estadística muy comúnmente utilizada a la hora de caracterizar y predecir el fracaso bancario ha sido el análisis discriminante. No obstante, es posible la utilización de otros métodos, como la regresión logística -o análisis logit- y el modelo probit -o normit- de respuesta cualitativa, ambos muy conocidos en economía y administración de empresas por su amplia aplicación en diferentes campos. Además, cabe servirse del modelo de riesgos proporcionales de Cox , del análisis envolvente de datos -más conocido por sus siglas en inglés, DEA- o de procedimientos multicriterio de ayuda a la decisión. Y también del amplio catálogo de técnicas de inteligencia artificial, como las redes neuronales y otros modelos o sistemas. Para una revisión de los diferentes tipos de análisis, son sus ventajas e inconvenientes, nos remitimos a Doumpos y Zopounidis (2002), Andrés Suárez (2005), Tascón Fernández y Castaño Gutiérrez (2012).

Desde un punto de vista empírico, parece que el análisis discriminante ha predominado en los estudios sobre las dificultades en entidades financieras. $\mathrm{Su}$ aplicación se remonta a la década de los pasados años setenta y, en la actualidad, no ha perdido protagonismo, tal vez por ser una técnica bien estudiada y, sobre todo, por los buenos resultados que ha aportado. Los primeros estudios sobre insolvencias bancarias se inspiraron fundamentalmente en los modelos de análisis discriminante estimados años atrás para empresas no financieras. Dicho de otro modo, siguieron la estela iniciada por el trabajo seminal de Altman (1968) y continuada con las importantes investigaciones de Meyer y Pifer (1970), Sinkey (1975), Ohlson (1980), Rose y Kolari (1985), etc. Posteriormente, se fue aplicando en el mismo campo otro tipo de técnicas, es especial la regresión logística, con trabajos iniciales como los Martin (1977) y Kolari y Zardkoohi (1987, cap. 7). En las aportaciones de, por ejemplo, Laffarga et al. (1987), Ahumada y Budnevich (1999), Sajter (2005), Jordan et al. (2010), Crespo (2011) y Muhammad (2012) pueden encontrarse revisiones específicas sobre la literatura especializada en insolvencias bancarias que se ha basado en el análisis discriminante o en la regresión logística.

Ciertamente, no procede presentar aquí expresamente un resumen de los muchos trabajos empíricos publicados con referencia a las dificultades financieras de instituciones de crédito en distintos sistemas bancarios nacionales. Máxime cuando en algunos casos -véase, por ejemplo, Demyanyk y Hasan (2009)- el repaso de esa literatura se amplía para relacionarla con las crisis financieras y cambiarias generales en un determinado país o en un conjunto más o menos 
extenso de países. No obstante, dado el objeto de estudio propio de la presente investigación, parece de interés intentar al menos recoger sintéticamente el contenido de algunos de los análisis empíricos específicos realizados hasta la fecha para el caso de las entidades de crédito españolas. Así se hace, siguiendo un orden cronológico, en la Tabla 2, donde se reflejan los elementos fundamentales de esos análisis: objetivo, muestra utilizada, variable dependiente, variables explicativas o independientes, técnica estadística o econométrica empleada y resultados alcanzados.

Como se observará a continuación, a medida que avanzamos en el tiempo los análisis realizados ponen más énfasis en unas u otras variables independientes, habida cuenta de la coyuntura económica general y de sus distintas vías de impacto sobre las instituciones bancarias. También influye el concepto de fracaso o dificultad financiera que en cada caso se aplica en función del objetivo del estudio.

\section{Tabla 2}

Resumen de algunos estudios efectuados sobre fracasos o insolvencias bancarias en España

\begin{tabular}{|c|c|c|c|c|c|c|}
\hline & Objetivo & Muestra & $\begin{array}{c}\text { Variable } \\
\text { dependiente }\end{array}$ & $\begin{array}{c}\text { Variables } \\
\text { independientes }\end{array}$ & $\begin{array}{c}\text { Técnica } \\
\text { empleada }\end{array}$ & Resultados \\
\hline $\begin{array}{c}\text { Laffarga et al. } \\
\quad(1987)\end{array}$ & $\begin{array}{l}\text { Comparación del } \\
\text { modelo lineal } \\
\text { discriminante y del } \\
\text { modelo logit a partir } \\
\text { del estudio de la } \\
\text { crisis bancaria } \\
\text { española de 1978- } \\
1983 \text {. }\end{array}$ & $\begin{array}{l}\text { Ratios } \\
\text { financieros de } 47 \\
\text { bancos (de los } \\
\text { cuales } 22 \text { fueron } \\
\text { intervenidos). }\end{array}$ & $\begin{array}{l}\text { Variable } \\
\text { dicotómica: } \\
\text { Entidad } \\
\text { intervenida por el } \\
\text { Fondo de } \\
\text { Garantía de } \\
\text { Depósitos (1)/ } \\
\text { no intervenida } \\
\text { (0). }\end{array}$ & $\begin{array}{l}\text { Cuatro ratios: créditos } \\
\text { más cartera de } \\
\text { valores/activo total; activo } \\
\text { fijo/activo total, reservas/ } \\
\text { pasivo total y beneficio } \\
\text { neto antes de } \\
\text { impuestos/activo total. }\end{array}$ & $\begin{array}{l}\text { Análisis } \\
\text { discriminante } \\
\text { y logit. }\end{array}$ & $\begin{array}{l}\text { La significación varia } \\
\text { sustancialmente de un } \\
\text { modelo a otro. El modelo } \\
\text { discriminante explica el } \\
99,2 \% \text { de la varianza de la } \\
\text { variable dependiente } \\
\text { mientras que el modelo logit } \\
\text { explica el } 99,5 \% \text {. El modelo } \\
\text { discriminante clasifica } \\
\text { correctamente el } 86,91 \% \text { de } \\
\text { los casos, mientras que el } \\
\text { modelo logit alcanza un } \\
93,40 \% \text {. }\end{array}$ \\
\hline $\begin{array}{c}\text { Rodríguez } \\
\text { (1989) }\end{array}$ & $\begin{array}{l}\text { Profundizar en el } \\
\text { conocimiento de } \\
\text { algunos aspectos } \\
\text { financieros de la } \\
\text { crisis española de } \\
\text { 1978-1983 a partir } \\
\text { de la identificación } \\
\text { de ratios contables } \\
\text { válidos que traten } \\
\text { de explicar las } \\
\text { insolvencias vividas } \\
\text { por algunos de los } \\
\text { bancos privados } \\
\text { españoles durante } \\
\text { ese período. }\end{array}$ & $\begin{array}{l}\text { Ratios derivados } \\
\text { de los datos } \\
\text { contables del } \\
\text { año } 1981 \text { de los } \\
\text { ochenta bancos } \\
\text { privados } \\
\text { españoles que al } \\
\text { terminar dicho } \\
\text { año funcionaban } \\
\text { con normalidad. }\end{array}$ & $\begin{array}{l}\text { Variable binaria: } \\
1 \text { si tiene lugar la } \\
\text { insolvencia } \\
\text { bancaria y } 0 \text { en } \\
\text { caso contrario. }\end{array}$ & $\begin{array}{l}\text { Quince ratios que recogen } \\
\text { los riesgos del activo } \\
\text { (crédito e inversión), de } \\
\text { transformación } \\
\text { (inmovilización, iliquidez y } \\
\text { margen), de operación, de } \\
\text { inadecuación del capital y } \\
\text { de falta de rentabilidad. } \\
\text { Tres forman el modelo } \\
\text { final estimado: } \\
\text { inmovilizado/activo total; } \\
\text { fondos propios } \\
\text { libres/inversiones } \\
\text { crediticias; y resultado } \\
\text { neto/ activo total medio. }\end{array}$ & $\begin{array}{l}\text { Análisis logit, } \\
\text { con método } \\
\text { de selección } \\
\text { paso a paso } \\
\text { de variables } \\
\text { explicativas. }\end{array}$ & $\begin{array}{l}\text { Se demuestra una fuerte } \\
\text { capacidad explicativa de una } \\
\text { combinación lineal de los } \\
\text { tres ratios incluidos en el } \\
\text { modelo. La aplicación del } \\
\text { modelo al propio colectivo de } \\
\text { estimación, con datos de un } \\
\text { año anterior a la } \\
\text { contingencia, presenta una } \\
\text { precisión clasificatoria total. } \\
\text { En sucesivas pruebas de } \\
\text { validación, las tasas de } \\
\text { clasificación correctas } \\
\text { oscilaron en el entorno entre } \\
\text { el } 91 \text { y el } 97 \text { por ciento. }\end{array}$ \\
\hline $\begin{array}{c}\text { Martínez et al. } \\
\text { (1989) }\end{array}$ & $\begin{array}{l}\text { Estimación de dos } \\
\text { modelos: modelo } \\
\text { predictivo sobre la } \\
\text { probabilidad de } \\
\text { crisis de una entidad } \\
\text { bancaria; modelo } \\
\text { de control, capaz de } \\
\text { identificar aquellas } \\
\text { actuaciones que a } \\
\text { corto plazo pueden } \\
\text { disminuir la } \\
\text { probabilidad real de } \\
\text { crisis. }\end{array}$ & $\begin{array}{l}\text { Datos } \\
\text { procedentes del } \\
\text { Anuario } \\
\text { Estadístico de la } \\
\text { Banca Privada } \\
\text { de un total de } 89 \\
\text { bancos durante } \\
\text { cuatro años } \\
\text { consecutivos (el } \\
\text { periodo } \\
\text { considerado para } \\
\text { cada banco } \\
\text { dependerá del } \\
\text { año de su crisis, } \\
\text { siendo éste } \\
\text { aleatorio para los } \\
\text { bancos sanos). }\end{array}$ & $\begin{array}{l}\text { Variable } \\
\text { dicotómica: } \\
\text { quiebra/no } \\
\text { quiebra }\end{array}$ & $\begin{array}{l}\text { Doce ratios contables que } \\
\text { recogen la estructura del } \\
\text { pasivo y su riesgo, riesgo } \\
\text { en divisas, cobertura de } \\
\text { riesgo, liquidez, } \\
\text { proporción de activo no } \\
\text { rentable, coeficiente de } \\
\text { garantía, coste medio del } \\
\text { pasivo, crecimiento de los } \\
\text { gastos generales, } \\
\text { apalancamiento financiero } \\
\text { y rentabilidad. } \\
\text { Adicionalmente, una } \\
\text { variable dicotómica que } \\
\text { toma el valor } 1 \text { si el banco } \\
\text { fue fundado antes de } \\
1964 \text { y } 0 \text { en caso } \\
\text { contrario. }\end{array}$ & $\begin{array}{l}\text { Diversos } \\
\text { modelos logit } \\
\text { para } \\
\text { diferentes } \\
\text { horizontes } \\
\text { temporales. }\end{array}$ & $\begin{array}{l}\text { Ambos modelos, tanto el de } \\
\text { predicción como el de } \\
\text { control, clasifican } \\
\text { correctamente el } 96,6 \% \text { de } \\
\text { los casos. No obstante, } \\
\text { mientras que en el primero } \\
\text { parecen ser significativos la } \\
\text { práctica totalidad de los } \\
\text { efectos recogidos por las } \\
\text { variables independientes, en } \\
\text { el segundo predominan } \\
\text { aquellos relativos al riesgo y } \\
\text { a la liquidez. }\end{array}$ \\
\hline
\end{tabular}


Tabla 2 (continuación)

Resumen de algunos estudios efectuados sobre fracasos o insolvencias bancarias en España

\begin{tabular}{|c|c|c|c|c|c|c|}
\hline & Objetivo & Muestra & $\begin{array}{c}\text { Variable } \\
\text { dependiente }\end{array}$ & $\begin{array}{c}\text { Variables } \\
\text { independientes }\end{array}$ & $\begin{array}{l}\text { Técnica } \\
\text { empleada }\end{array}$ & Resultados \\
\hline $\begin{array}{l}\text { Pina } \\
\text { (1989) }\end{array}$ & $\begin{array}{l}\text { Estudiar si la } \\
\text { información } \\
\text { contable de las } \\
\text { entidades bancarias } \\
\text { españolas es válida } \\
\text { para predecir } \\
\text { quiebras en el } \\
\text { sector. }\end{array}$ & $\begin{array}{l}\text { Datos financieros } \\
\text { procedentes del } \\
\text { Anuario } \\
\text { Estadístico de la } \\
\text { Banca Privada } \\
\text { para los años } \\
\text { 1975-1981. }\end{array}$ & $\begin{array}{l}\text { Variable } \\
\text { dicotómica: } \\
\text { banco sano (1) / } \\
\text { banco en crisis } \\
\text { (0). }\end{array}$ & $\begin{array}{l}\text { Nueve ratios contables: } \\
\text { liquidez, } \\
\text { autofinanciación, } \\
\text { rentabilidad económica, } \\
\text { rentabilidad financiera, } \\
\text { apalancamiento, coste } \\
\text { de venta y liquidez. }\end{array}$ & $\begin{array}{l}\text { Modelo de } \\
\text { regresión lineal } \\
\text { para selección } \\
\text { inicial de ratios. } \\
\text { Varios modelos } \\
\text { logit, con método } \\
\text { de selección } \\
\text { paso a paso de } \\
\text { variables } \\
\text { independientes. }\end{array}$ & $\begin{array}{l}\text { La construcción de un } \\
\text { modelo con información } \\
\text { combinada de tres años } \\
\text { consecutivos clasifica } \\
\text { correctamente la totalidad de } \\
\text { la muestra. En cualquier } \\
\text { caso, la mayor capacidad } \\
\text { explicativa parece } \\
\text { encontrarse en los ratios de } \\
\text { liquidez y rentabilidad. }\end{array}$ \\
\hline $\begin{array}{l}\text { Serrano y } \\
\text { Martín } \\
(1993)\end{array}$ & $\begin{array}{l}\text { Estudiar las } \\
\text { ventajas e } \\
\text { inconvenientes de } \\
\text { las redes } \\
\text { neuronales frente a } \\
\text { los tradicionales } \\
\text { modelos y técnicas } \\
\text { estadisticas de } \\
\text { clasificación. }\end{array}$ & $\begin{array}{l}\text { Datos } \\
\text { procedentes del } \\
\text { Anuario } \\
\text { Estadístico de la } \\
\text { Banca Privada } \\
\text { para } 66 \text { bancos. } \\
\text { La información } \\
\text { para los } 29 \\
\text { quebrados que } \\
\text { componen la } \\
\text { muestra es de un } \\
\text { año antes de } \\
\text { tener lugar su } \\
\text { quiebra, mientras } \\
\text { que la } \\
\text { información de } \\
\text { los } 37 \text { no } \\
\text { quebrados es de } \\
1982 \text {. Dos } \\
\text { submuestras: } \\
\text { una de } \\
\text { aprendizaje y } \\
\text { otra de test. }\end{array}$ & No procede. & $\begin{array}{l}\text { Nueve ratios contables: } \\
\text { liquidez, } \\
\text { autofinanciación, } \\
\text { rentabilidad financiera, } \\
\text { rentabilidad económica, } \\
\text { apalancamiento, coste } \\
\text { de venta y liquidez. } \\
\text { Alternativamente, en el } \\
\text { modelo neuronal de } \\
\text { mapas } \\
\text { autoorganizados se } \\
\text { emplearon ocho datos } \\
\text { financieros escalados. }\end{array}$ & $\begin{array}{l}\text { Construcción de } \\
\text { dos modelos } \\
\text { neuronales: } \\
\text { perceptrón } \\
\text { multicapa y } \\
\text { mapas } \\
\text { autoorganizados. }\end{array}$ & $\begin{array}{l}\text { El perceptrón multicapa } \\
\text { muestra una buena } \\
\text { capacidad predictiva en el } \\
\text { corto plazo, con un } \\
\text { porcentaje de acierto } \\
\text { cercano al } 94 \% \text { de los } \\
\text { casos. Ambos modelos } \\
\text { neuronales pueden ser } \\
\text { complementarios, } \\
\text { permitiendo los mapas } \\
\text { autoorganizados estudiar la } \\
\text { evolución de las entidades } \\
\text { en el tiempo. No obstante, } \\
\text { existen bancos con ratios } \\
\text { similares pero con un final } \\
\text { distinto: quiebra/no quiebra. } \\
\text { Las redes neuronales, en } \\
\text { estos casos, no son capaces } \\
\text { de aprender el patrón y dar } \\
\text { una respuesta coherente. }\end{array}$ \\
\hline $\begin{array}{l}\text { Sagarra et al. } \\
\text { (2011) }\end{array}$ & $\begin{array}{l}\text { Conocer si existian } \\
\text { debilidades } \\
\text { financieras previas } \\
\text { en las cajas de } \\
\text { ahorros españolas } \\
\text { que han necesitado } \\
\text { ayuda durante la } \\
\text { actual crisis } \\
\text { financiera. }\end{array}$ & $\begin{array}{l}\text { Datos contables } \\
\text { obtenidos de la } \\
\text { base de datos } \\
\text { Bankscope para } \\
\text { un conjunto de } \\
43 \text { cajas de } \\
\text { ahorros } \\
\text { españolas en el } \\
\text { año } 2006 . \\
\text { Adicionalmente, } \\
\text { datos contables } \\
\text { de cuatro cajas } \\
\text { de ahorros (dos } \\
\text { problemáticas } \\
\text { frente a dos sin } \\
\text { problemas) entre } \\
\text { los años } 1999 \text { y } \\
2008 . \\
\end{array}$ & $\begin{array}{l}\text { Análisis logit con } \\
\text { variable } \\
\text { dicotómica: no } \\
\text { rescate }(1) \text { ó } \\
\text { rescate }(0) .\end{array}$ & $\begin{array}{l}22 \text { ratios financieros (5 } \\
\text { de solvencia, } 5 \text { de } \\
\text { rentabilidad, } 4 \text { de } \\
\text { liquidez, } 4 \text { de riesgo o } \\
\text { calidad del activo y } 4 \\
\text { de tamaño y } \\
\text { crecimiento). Y dos } \\
\text { medidas de eficiencia } \\
\text { aplicando el método } \\
\text { DEA (Data } \\
\text { Envelopment Analysis). }\end{array}$ & $\begin{array}{l}\text { Análisis factorial } \\
\text { de las variables } \\
\text { para reducir } \\
\text { dimensiones. } \\
\text { Análisis logit. }\end{array}$ & $\begin{array}{l}\text { Los análisis ponen de } \\
\text { manifiesto que las cajas de } \\
\text { ahorros que han tenido } \\
\text { problemas durante la actual } \\
\text { crisis financiera presentan, } \\
\text { por lo general, los niveles } \\
\text { más bajos de solvencia, } \\
\text { rentabilidad y eficiencia, así } \\
\text { como los mayores niveles de } \\
\text { riesgo asumido. }\end{array}$ \\
\hline $\begin{array}{l}\text { Climent } \\
(2013)\end{array}$ & $\begin{array}{l}\text { Conocer cómo han } \\
\text { influido las masas } \\
\text { patrimoniales de los } \\
\text { balances (además } \\
\text { del tamaño y la } \\
\text { estructura de } \\
\text { propiedad) en la } \\
\text { evolución de la } \\
\text { solvencia de las } \\
\text { entidades } \\
\text { financieras } \\
\text { españolas desde el } \\
\text { año 2006, antes del } \\
\text { inicio de la crisis } \\
\text { financiera } \\
\text { internacional, hasta } \\
\text { el año 2009, } \\
\text { comienzo de los } \\
\text { procesos de } \\
\text { reestructuración. }\end{array}$ & $\begin{array}{l}\text { Datos contables } \\
\text { de las } 59 \\
\text { entidades de } \\
\text { crédito que } \\
\text { conforman la } \\
\text { muestra, desde } \\
\text { el año } 2006 \\
\text { hasta el año } \\
2009 .\end{array}$ & $\begin{array}{l}\text { Análisis de } \\
\text { regresión: } \\
\text { coeficiente de } \\
\text { solvencia. } \\
\text { Análisis } \\
\text { discriminante: } \\
\text { variable } \\
\text { dicotómica: } \\
\text { bancos y cajas } \\
\text { de ahorros. }\end{array}$ & $\begin{array}{l}\text { Crecimiento de los } \\
\text { créditos respecto al } \\
\text { crecimiento del PIB, } \\
\text { empresas participadas, } \\
\text { activos ponderados por } \\
\text { riesgo, depósitos de } \\
\text { bancos centrales, } \\
\text { débitos en pasivos } \\
\text { negociables, tasa de } \\
\text { morosidad ajustada } \\
\text { con la cobertura, } \\
\text { depósitos de clientes, } \\
\text { exposición al sector } \\
\text { inmobiliario, } \\
\text { rentabilidad de los } \\
\text { fondos propios, forma } \\
\text { jurídica (bancos o cajas } \\
\text { de ahorros) y tamaño. }\end{array}$ & $\begin{array}{l}\text { Inicialmente un } \\
\text { análisis } \\
\text { descriptivo y de } \\
\text { regresión para } \\
\text { obtener las } \\
\text { variables } \\
\text { relevantes. } \\
\text { Posteriormente, } \\
\text { un análisis } \\
\text { discriminante } \\
\text { utilizando como } \\
\text { variables } \\
\text { independientes } \\
\text { las significativas } \\
\text { en el análisis de } \\
\text { regresión } \\
\text { anterior. }\end{array}$ & $\begin{array}{l}\text { Ambos análisis parecen } \\
\text { demostrar que existen } \\
\text { diferencias en los niveles de } \\
\text { solvencia entre bancos y } \\
\text { cajas de ahorros. Según los } \\
\text { resultados obtenidos, los } \\
\text { bancos muestran una mejor } \\
\text { solvencia que las cajas. Los } \\
\text { factores que más } \\
\text { negativamente afectan a la } \\
\text { solvencia de las entidades } \\
\text { son la morosidad y la } \\
\text { dependencia de los } \\
\text { mercados mayoristas de } \\
\text { fondos. }\end{array}$ \\
\hline
\end{tabular}


Tabla 2 (continuación)

Resumen de algunos estudios efectuados sobre fracasos o insolvencias bancarias en España

\begin{tabular}{|c|c|c|c|c|c|c|}
\hline & Objetivo & Muestra & $\begin{array}{c}\text { Variable } \\
\text { dependiente }\end{array}$ & $\begin{array}{c}\text { Variables } \\
\text { independientes }\end{array}$ & $\begin{array}{l}\text { Técnica } \\
\text { empleada }\end{array}$ & Resultados \\
\hline $\begin{array}{c}\text { Gutiérrez y } \\
\text { Abad } \\
\text { (2013) }\end{array}$ & $\begin{array}{l}\text { Comprobar si la } \\
\text { información } \\
\text { recogida en los } \\
\text { estados contables } \\
\text { de las entidades } \\
\text { bancarias españolas } \\
\text { y/o en documento } \\
\text { de información con } \\
\text { relevancia } \\
\text { prudencial permitia } \\
\text { predecir los } \\
\text { resultados de los } \\
\text { tests de estrés o } \\
\text { pruebas de } \\
\text { resistencia, medidas } \\
\text { éstas en términos } \\
\text { de exceso o déficit } \\
\text { de capital, en los } \\
\text { escenarios base y } \\
\text { adverso. }\end{array}$ & $\begin{array}{l}\text { Estados } \\
\text { contables } \\
\text { públicos e } \\
\text { información con } \\
\text { relevancia } \\
\text { prudencial de un } \\
\text { total de } 25 \\
\text { entidades de } \\
\text { crédito } \\
\text { españolas ( } 7 \\
\text { bancos y } 18 \\
\text { cajas). }\end{array}$ & $\begin{array}{l}\text { Variable binaria: } \\
\text { toma valor } 1 \mathrm{si} \\
\text { existen } \\
\text { necesidades de } \\
\text { capital; y } 0 \text { en } \\
\text { caso contrario. }\end{array}$ & $\begin{array}{l}\text { Análisis 1: rentabilidad } \\
\text { del activo, rentabilidad } \\
\text { de los fondos propios, } \\
\text { intereses y } \\
\text { rendimientos } \\
\text { asimilados/ inversiones } \\
\text { crediticias, fondos } \\
\text { propios/pasivo, } \\
\text { inversiones crediticias+ } \\
\text { cartera de valores/ } \\
\text { fondos propios, gastos } \\
\text { de explotación/margen } \\
\text { de explotación, } \\
\text { inversiones } \\
\text { crediticias/activo, } \\
\text { tesorería/ recursos } \\
\text { ajenos. Análisis } 2: \\
\text { recursos propios } \\
\text { básicos/ recursos } \\
\text { propios computables, } \\
\text { requerimientos por } \\
\text { riesgo de } \\
\text { crédito/requerimientos } \\
\text { totales, exposición al } \\
\text { riesgo de crédito/ } \\
\text { activo. }\end{array}$ & $\begin{array}{l}\text { Regresión } \\
\text { logística } \\
\text { estándar y } \\
\text { exacta con } \\
\text { método de } \\
\text { selección paso a } \\
\text { paso de } \\
\text { variables } \\
\text { independientes. } \\
\text { Dos análisis, } \\
\text { según sean las } \\
\text { variables } \\
\text { independientes } \\
\text { consideradas. }\end{array}$ & $\begin{array}{l}\text { Los modelos clasifican } \\
\text { correctamente entre el } 85 \% \\
\text { y el } 90 \% \text { de los casos. Los } \\
\text { resultados muestran que } \\
\text { tanto la estructura } \\
\text { patrimonial de las entidades } \\
\text { como la calidad del capital } \\
\text { son las variables con mayor } \\
\text { capacidad predictiva. De tal } \\
\text { modo que, cuanto menor es } \\
\text { la proporción de recursos } \\
\text { propios frente a ajenos, o } \\
\text { cuanto menor es la calidad } \\
\text { de esos recursos propios, } \\
\text { mayor es la probabilidad de } \\
\text { que la entidad requiera } \\
\text { capital adicional. }\end{array}$ \\
\hline
\end{tabular}

Fuente: Elaboración propia.

\section{DISEÑO DE LA INVESTIGACIÓN EMPÍRICA}

Como se apuntó en la introducción, el objetivo de la investigación empírica aquí presentada es estimar un modelo que identifique algunos elementos determinantes o explicativos de las dificultades financieras experimentadas por diversas instituciones de depósito en España durante los últimos años, tal que puedan ser de interés para el futuro, como indicadores en un sistema de alerta temprana. A estos efectos, la muestra inicial contó con datos de los tres tipos de entidades existentes en el sistema bancario español: bancos, cajas de ahorros y cooperativas de crédito, siendo estas últimas cajas populares o profesionales y cajas rurales.

En concreto, en esa muestra inicial se incluyeron 192 instituciones: 66 bancos, 45 cajas de ahorros y 81 cooperativas de crédito. Los correspondientes datos económico-financieros considerados relevantes a efectos de la presente investigación se detallan más adelante. Provienen de sus estados financieros públicos, facilitados por la Confederación Española Cajas de Ahorros (CECA), la Asociación Española de Banca (AEB), la Unión Nacional de Cooperativas de Crédito (UNACC) y las propias entidades.

Siguiendo el proceder habitual en la estimación de este tipo de modelos empíricos, la información recogida es anterior al suceso (dificultades financieras) analizado, para que el modelo posteriormente estimado pueda calificarse de "alerta temprana o previa". Téngase presente que el perfil económico-financiero de una institución cuando ya está en unas circunstancias difíciles suele ser bas- 
tante diferente al que mostraba antes llegar a ella, pese a que pudiera estar latente esa situación. En consecuencia, los pertinentes datos se reunieron para los dos años, 2008 y 2009, previos a las dificultades financieras de diferentes instituciones en los respectivos años inmediatamente posteriores, esto es, 2009 y 2010. De este modo, la muestra inicial contenía 384 "individuos o casos", es decir, 192 entidades para el año 2008 y otras 192 para el año 2009. Sin embargo, tras un análisis de los datos recogidos, fue preciso prescindir de algunas entidades por carecer de la información necesaria. Además, conviene trabajar con una muestra de análisis y otra de validación, a la vez que ha de disponerse de suficientes instituciones fracasadas y no fracasadas en cada una de esas dos muestras y a lo largo de los dos años correspondientes. Y, así, finalmente, después de aplicar un procedimiento de selección aleatoria, se trabajó con una muestra de estimación constituida por 190 casos, siendo 140 entidades sanas y 50 instituciones con dificultades financieras; y una muestra de validación formada por 170 casos, en concreto 131 entidades sanas y 39 instituciones fracasadas.

A cada uno de los individuos o casos se le asignó un grupo de pertenencia, en función de su situación en el año siguiente al ejercicio económico al que corresponden los datos. Dicho grupo de pertenencia se traduce en la variable dependiente, o a explicar, en el modelo objeto de estimación, y tiene carácter binario. Adopta dos valores: uno ("fracaso"), si la entidad se encontró inmersa en dificultades financieras, entendiendo por éstas tener un déficit de capital y/o entrar en trámites de fusión por dicha circunstancia, o recibir ayudas públicas, o ser intervenida por el Banco de España y/o nacionalizada -control accionarial en manos del FROB, del cual hablamos anteriormente-; y cero ("sana") en caso contrario, es decir, cuando no se encontró en alguna de esas circunstancias. La clasificación en cada uno de los dos grupos de pertenencia se ha realizado a partir de las informaciones publicadas en los anuarios de la Confederación Española de Cajas de Ahorros (2007-2013), la Asociación Española de Banca (2007-2013) y la Unión Nacional de Cooperativas de Crédito (2007-2013), así como en el informe anual del Banco de España (2008-2011).

Las variables explicativas o independientes inicialmente consideradas fueron las siguientes: a) veintiséis ratios contables de carácter económico-financiero, calculados a partir de las cuentas anuales de las respectivas entidades; b) siete variables de control, en concreto dos representativas del tamaño de la entidad, cuatro para reflejar expresamente la coyuntura económica general -tomando como fuente al Instituto Nacional de Estadística- y una medida temporal a través de una variable artificial (dummy) denominada año, con la finalidad que más adelante se detallará. Este conjunto de variables explicativas se recoge en la 
Tabla 3, clasificadas en cuatro categorías ${ }^{4}$. Para especificarlas, ante todo se procedió a repasar los determinantes económico-financieros microeconómicos -individuales- del fracaso bancario que han sido detectados hasta ahora en estudios empíricos previos efectuados con instituciones españolas o extranjeras. Y también se tuvieron en cuenta las ya apuntadas características que rodearon la expansión del sistema bancario de España durante los años anteriores a la Gran Recesión iniciada en 2007.

Tabla 3

Variables explicativas consideradas inicialmente en la investigación

\begin{tabular}{|c|c|}
\hline Variables & Definición \\
\hline \multicolumn{2}{|c|}{ Variable artificial de control temporal } \\
\hline AÑO & Año \\
\hline \multicolumn{2}{|c|}{ Variables de control de la coyuntura económica general } \\
\hline LNPIBpc & $\begin{array}{l}\text { Logaritmo neperiano del Producto Interior Bruto a precios de mercado por } \\
\text { habitante en miles de euros }\end{array}$ \\
\hline TP & Tasa de desempleo (\%) \\
\hline LNRNDpc & $\begin{array}{l}\text { Logaritmo neperiano de la renta nacional disponible neta a precios de mercado por habitante } \\
\text { en miles de euros }\end{array}$ \\
\hline PII & Posición de inversión internacional neta en \% del PIB a precios de mercado \\
\hline \multicolumn{2}{|c|}{ Variables de control de tamaño } \\
\hline LNTA & Logaritmo neperiano del total activo en miles de euros \\
\hline LNFP & Logaritmo neperiano de los fondos propios en miles de euros \\
\hline \multicolumn{2}{|c|}{ Ratios económico-financieros (en tanto por uno) } \\
\hline R1 & Fondos propios/ total activo \\
\hline R2 & Fondos propios/ créditos a la clientela \\
\hline R3 & Beneficio neto/ total activo \\
\hline R4 & Beneficio neto/ fondos propios \\
\hline R5 & Créditos a la clientela/ depósitos de la clientela \\
\hline R6 & Créditos a la clientela/ total activo \\
\hline R7 & Tasa de crecimiento del total activo \\
\hline R8 & Tasa de crecimiento de los fondos propios \\
\hline R9 & Tasa de crecimiento de los créditos a la clientela \\
\hline R10 & Tasa de crecimiento del beneficio neto \\
\hline R11 & (Fondos propios-activo material)/ total activo \\
\hline R12 & Pérdidas por deterioro de inversiones crediticias/ créditos a la clientela \\
\hline
\end{tabular}

${ }^{4}$ En algún momento, también se estudió la posible inclusión de una variable dummy para reflejar las distintas formas generales de gobierno corporativo, según la entidad fuera caja de ahorros, banco o cooperativa de crédito. Sin embargo, debido a la excesiva concentración de las entidades consideradas problemáticas en el colectivo de las cajas de ahorros, los métodos de selección de variables explicativas que más adelante se señalan optaban de inmediato por elegirla como determinante único del fenómeno estudiado. Se desembocaba así en la estimación de un modelo "ingenuo" que desvirtuaba la finalidad original del estudio, máxime considerando que el objetivo principal de éste siempre fue la identificación de indicadores económico-financieros microeconómicos y variables macroeconómicas, aparte de los consabidos inconvenientes asociados con el sistema de gobierno corporativo que se ha venido aplicando en las cajas de ahorros (al respecto, véase, por ejemplo, Serra Ramoneda, 2011; Rodríguez Fernández, 2012). 
Tabla 3 (continuación)

Variables explicativas consideradas inicialmente en la investigación

\begin{tabular}{|c|l|}
\hline Variables & \multicolumn{1}{|c|}{ Definición } \\
\hline \multicolumn{2}{|c|}{ Ratios económico-financieros (en tanto por uno) } \\
\hline R13 & Provisiones/ créditos a la clientela \\
\hline R14 & Provisiones/ patrimonio neto \\
\hline R15 & (Dotación a provisiones+ pérdidas por deterioro de activos financieros)/ margen bruto \\
\hline R16 & (Dotación a amortizaciones+ gastos de administración)/ margen bruto \\
\hline R17 & Caja y depósitos en bancos centrales/ total activo \\
\hline R18 & Caja y depósitos en bancos centrales/ total financiación ajena \\
\hline R19 & Activo material/ total activo \\
\hline R20 & Pérdidas por deterioro de activos financieros/ total activo \\
\hline R21 & (Créditos a la clientela- depósitos de la clientela)/ margen de intereses \\
\hline R22 & Resultado de las actividades de explotación/ total activo \\
\hline R23 & Resultado de las actividades de explotación/ fondos propios \\
\hline R24 & (Inversiones inmobiliarias+ activos no corrientes en venta+ resto activos) $/$ total activo \\
\hline R25 & Inversiones inmobiliarias/ total activo \\
\hline R26 & Tasa de crecimiento de las inversiones inmobiliarias \\
\hline
\end{tabular}

Fuente: Elaboración propia.

Finalmente, en el momento de elegir la técnica econométrica o de estadística multivariante a aplicar en la estimación del modelo empírico, se optó por el análisis discriminante, de acuerdo con la senda seguida por las primeras aportaciones en este campo de investigación. Además de que, en su versión lineal, es una técnica bien conocida y que no requiere especiales explicaciones, sus resultados a lo largo del tiempo han sido muy apreciables. Conforme en seguida se apuntará, la dificultad existente en la práctica para que se cumplan sus restrictivos supuestos de partida puede no ser un inconveniente tan grave como podría parecer a primera vista, dada su relativa robustez ante la violación de los mismos. No obstante, a la vista de la gran difusión que en los últimos tiempos han tenido los modelos econométricos de respuesta cualitativa como el probit o normit y, sobre todo, el logit, también se procedió a aplicar los correspondientes métodos de estimación, con las mismas variables especificadas en la función discriminante lineal que más abajo se presenta. Pues bien, la calidad estadística de sus resultados no superó la alcanzada utilizando la técnica del análisis discriminante.

Se utilizó el paquete SPSS de programas estadísticos y econométricos. Y, descendiendo a los detalles sobre la metodología discriminante aplicada, cabe

\footnotetext{
${ }^{5}$ Para obtener la exposición total al "ladrillo y cemento", incluso más allá de las inversiones inmobiliarias, se tuvieron en cuenta los tres epígrafes del balance donde la instituciones bancarias registran sus activos relacionados con la construcción y los negocios inmobiliarios: en concreto, las propias inversiones inmobiliarias, los activos no corrientes en venta (los denominados adjudicados) y el resto de activos similares, es decir, terrenos y demás propiedades que se tienen para la venta en la actividad de promoción inmobiliaria.
} 
aclarar que:

En primer lugar, se seleccionaron aquellas variables explicativas más relevantes para formar parte del modelo estimado, intentando que éste tuviera la mayor capacidad posible para discriminar entre entidades sanas e instituciones con dificultades financieras y, a la vez, que fuese parsimonioso. Para este fin, se utilizó un doble procedimiento, dejando siempre aparte la variable artificial "año": en un primer momento, un método de selección "paso a paso", mediante contrastes basados en la lambda de Wilks y en la distancia $\mathrm{D}^{2}$ de Mahalanobis, coincidiendo los resultados; después, para confirmar el conjunto de variables derivado del procedimiento "paso a paso" previo -el cual no necesariamente conduce siempre a una selección óptima-, se aplicó un método exhaustivo de análisis de los diversos subconjuntos posibles, cuyo resultado revalidó la elección de variables explicativas efectuada con el primer método.

La estimación propiamente dicha del modelo discriminante lineal se efectuó dos veces. Ante todo, con el conjunto de variables independientes seleccionado de acuerdo con los procedimientos señalados en el párrafo precedente. En un segundo momento, se reestimó la función discriminante controlando la nueva estimación mediante la variable artificial denominada "año". Se procedió así en un intento de tener en cuenta otros posibles componentes de la evolución temporal de la coyuntura económica general capaces de tener influencia sobre el fenómeno estudiado, más allá de los derivados de las variables de control explícitamente consideradas para reflejar esa coyuntura. Dentro del proceso de selección de variables explicativas antes aludido, nunca resultaron ser estadísticamente significativas estas variables de control expresamente especificadas para esa finalidad, pese al exhaustivo análisis realizado con subconjuntos de variables explicativas. Sin embargo, podrían existir otros determinantes macroeconómicos susceptibles de generar algún efecto, siendo la variable de control "año" una manera indirecta de tenerlos presente. Y, así, en el epígrafe de resultados empíricos se presenta la función discriminante lineal estimada controlando por el efecto de la variable artificial "año". Ahora bien, cabe subrayar que, en realidad, no se desembocó en unos resultados diferentes de los alcanzados sin efectuar ese control: los coeficientes de las variables explicativas dentro la función estimada sólo se modifican en algunos decimales, sin cambios en las tasas de error calculadas ni en la significación de los contrastes estadísticos efectuados.

\section{RESULTADOS EMPÍRICOS}

Conforme a los usos habituales, ante todo se analizaron los datos muestrales mediante el cálculo de los correspondientes estadísticos descriptivos y la matriz de correlaciones bivariadas de Pearson, incluyendo sus niveles de significación 
en prueba bilateral. También se aprovechó para intentar identificar posibles casos atípicos (ouliers), sin detectase alguno verdaderamente significativo.

A continuación, ya al hilo del proceso de estimación de la función discriminante lineal, se procedió a comprobar el cumplimiento, o no, de dos hipótesis asociadas con el análisis discriminante lineal de carácter multivariante: normalidad multivariante e igualdad de la matriz de varianzas y covarianzas de los dos grupos de pertenencia reflejados en la variable dependiente $(0,1)$.

Como la normalidad multivariante exige la previa normalidad de las variables individualmente consideradas, se efectuaron los correspondientes contrastes de Kolmogorov-Smirnov, con la corrección de Lilliefors. Se rechazó la hipótesis de normalidad en la mayoría de las variables analizadas, como era previsible por ser la pauta habitual en el caso de variables explicativas en forma de ratios económico-financieros, según se ha podido comprobar en numerosos estudios previos efectuados al respecto (véase, por ejemplo, Andrés Suárez, 2001).

En cuanto al citado supuesto de igualdad de la matriz de varianzas y covarianzas, para su verificación se recurrió al contraste de la $\mathrm{M}$ de Box mediante su estadístico $\mathrm{F}$ aproximado, rechazándose la hipótesis nula de igualdad de esa matriz. En esta situación, cabe estimar una función discriminante cuadrática en vez de lineal. Ahora bien, en la presente investigación el recurso a esta última forma de análisis, mediante la utilización de varios programas apropiados para ello -incluidos en concreto en cuatro paquetes estadísticos y econométricos distintos del SPSS-, no ofreció resultados estadísticamente mejores que los obtenidos a través de la técnica del análisis discriminante lineal. Tal vez porque sería conveniente contar con un mayor tamaño muestral del grupo de entidades fracasadas, a la vista de los muchos más coeficientes o parámetros que han de estimarse en el caso de la función cuadrática.

En cuanto a la hipótesis de no multicolinealidad -otro de los supuestos más relevantes en el análisis discriminante-, el propio procedimiento de selección de variables explicativas aquí aplicado tiende a reducir drásticamente el riesgo de relaciones colineales entre esas variables.

Según acabamos de señalar, no se cumplen algunas de las hipótesis del análisis discriminante. Ahora bien, aun en este tipo de situaciones, dicho análisis discriminante suele proporcionar un resultado satisfactorio, debido a que, por lo general, la correspondiente función discriminante estimada tiende a ser relativamente robusta frente a la no verificación de esos supuestos de partida, incluyendo la ausencia de normalidad (Klecka, 1980), sobre todo si esta última no llega a ser demasiado grave (Pohar et al., 2004).

Una vez realizado todo el proceso de estimación antes detallado, las variables explicativas seleccionadas fueron cuatro, lo cual implica un modelo muy parsimonioso, característica casi siempre muy de apreciar y que es similar al 
caso de otros estudios empíricos previos. La correspondiente función discriminante lineal estimada, con los coeficientes y signos de esas variables, así como la correlación canónica, se presenta en la Tabla 4. Un signo positivo representa una mayor probabilidad de fracaso o dificultades financieras. Y, así, la media de las puntuaciones de la función discriminante ("centroide"), calculada con sus coeficientes no estandarizados, fue de 1,559 en el grupo de entidades con problemas. El centroide en el grupo de entidades sanas fue de -0,557. Por su parte, los coeficientes estandarizados o tipificados facilitan conocer la importancia relativa de cada variable, es decir, interpretar su poder discriminante. La lambda de Wilks, también reflejada en la Tabla 4 -junto con su transformación chi-cuadrado-, contrasta la hipótesis nula de igualdad de los centroides, de modo que su aceptación implicaría que el modelo estimado no sería capaz de diferenciar entre grupos. Como se observa, se rechaza esa hipótesis nula para cualquiera de los niveles de significación habitualmente utilizados.

Los mencionados centroides o valores promedio, ponderados por las probabilidades a priori de cada grupo, permiten establecer el cut-off point o punto de corte discriminante, que cabe utilizar como referencia a la hora de clasificar a las diferentes entidades en uno u otro grupo. A estos efectos, se tomaron como probabilidades a priori las proporciones de instituciones fracasadas y sanas en la muestra de estimación, es decir, 0,2632 y 0,7368, respectivamente. Las proporciones son muy similares si las calculamos sobre la muestra total, o sea, de estimación y validación, pues entonces serían 0,25 y 0,75 .

Tabla 4

Coeficientes de la función discriminante lineal (canónica)

\begin{tabular}{|c|c|c|c|c|}
\hline & \multicolumn{2}{|c|}{$\begin{array}{c}\text { Coeficientes } \\
\text { estandarizados }\end{array}$} & \multicolumn{2}{|c|}{$\begin{array}{l}\text { Coeficientes no } \\
\text { estandarizados }\end{array}$} \\
\hline LNTA & & 1,039 & & 0,553 \\
\hline $\mathbf{R 8}$ & & $-0,369$ & & $-2,850$ \\
\hline R19 & & 0,579 & & 52,838 \\
\hline R26 & & 0,275 & & 0,092 \\
\hline (Constante) & & & & $-8,697$ \\
\hline Lambda de Wilks & Chi-cuadrado & \multicolumn{2}{|c|}{ GI } & Sig. \\
\hline ,533 & 116,877 & & 5 &, 000 \\
\hline Autovalor & $\%$ de varianza & $\%$ act & Iulado & $\begin{array}{c}\text { Correlación } \\
\text { canónica }\end{array}$ \\
\hline ,878 & 100,0 & & 100,0 & ,684 \\
\hline
\end{tabular}

Estimación controlada por el efecto de la variable artificial "año".

Fuente: Elaboración propia.

Procede comentar ahora el contenido y el signo de las cuatro variables explicativas incluidas en la función discriminante estimada. En concreto: 
- LNTA (logaritmo neperiano del total activo): Signo positivo. Variable de control, como medida del tamaño de las entidades. Sugiere que las situaciones problemáticas se concentraron con bastante frecuencia en instituciones de un tamaño considerable. Aunque es verdad que quedaron al margen los grandes bancos comerciales españoles, no es menos cierto que se vieron afectadas cajas de ahorros tan importantes como Caja Madrid, Caixa Catalunya, Caja de Ahorros del Mediterráneo, etc. En otros trabajos, como es el caso de Climent (2013) -recogido en la Tabla 2-, el tamaño de la entidad también resultó ser significativo; sin embargo, en su estudio la relación entre dicho tamaño y el riesgo de fracaso es inversa.

- R8: Signo negativo. Tasa de crecimiento anual de los fondos propios, magnitud que guarda estrecha relación en la muestra analizada con la capacidad de las entidades para generar beneficios y autofinanciarse. Aquellas instituciones de depósito que más se esforzaron por consolidar y aumentar sus recursos propios han tenido menor probabilidad hallarse en una situación comprometida. Viene a confirmar el resultado alcanzado por Gutiérrez y Abad (2013), si bien, como quedó reflejado en la Tabla 2, éstos utilizaron una muestra muy limitada.

- R19: Signo positivo. Ratio que representa la estructura del activo, más en concreto se refiere al peso del activo material dentro del activo total, y parece ser la variable más determinante. La partida 13 del balance bancario recoge el activo material entendido como la suma del inmovilizado material y las inversiones inmobiliarias. Este ratio coincide con lo detectado en estudios españoles previos (Lafarga et al., 1987; Rodríguez, 1989) sobre la importancia de contener y limitar el volumen de los activos fijos y las inversiones inmobiliarias en las entidades bancarias. El hecho de que se hayan vuelto a reproducir recientemente ciertas situaciones de dificultades financieras por causas similares a las observadas en otras épocas confirman una vez más el acierto de Galbraith (1991), cuando aseguró que los absurdos comportamientos humanos que inducen episodios recurrentes de demencia financiera vienen siendo los mismos desde la "burbuja de los tulipanes" en los Países Bajos, entre 1636 y 1637.

- R26: Signo positivo. Tasa de crecimiento de las inversiones inmobiliarias realizadas por la entidad. Como era de esperar, aquellas instituciones de depósito que incluso siguieron aumentando sus esfuerzos inversores en el sector inmobiliario durante el periodo estudiado, han visto incrementarse sus posibilidades de encontrarse en situaciones de riesgo.

Las variables de control de la coyuntura económica general no parecen tener una capacidad discriminante lo suficientemente elevada como formar parte de la pertinente función, quedando eclipsadas por aquellas que en último término resultan seleccionadas a estos efectos. Probablemente, esto indica que la debili- 
dad de las entidades que han sufrido dificultades financieras tenía un carácter estructural, derivada del modelo de negocio mantenido desde hace tiempo. La negativa o frágil coyuntura económica general ha podido actuar ahora como elemento desencadenante -e incluso propagador- del incendio, pero el combustible acumulado tenía otra procedencia. Lo mismo parece sugerir el hecho de que tampoco varíe significativamente la estimación si se introduce "año" como variable artificial genérica de control temporal.

Por otra parte, como queda recogido en la Tabla 2, se ha resaltado la dependencia de los mercados de fondos al por mayor como elemento generador de crisis bancarias. Esta dependencia será mayor cuanto más elevado sea el ratio R5. Sin embargo, en la muestra aquí analizada, el valor medio de este ratio es superior en las instituciones sanas. Esto permite vislumbrar que, en sí, el riesgo no nace tanto del volumen relativo de fondos de ese tipo utilizados, cuanto del uso que a su vez se haga de los mismos, como por lo demás es bastante lógico: obviamente, así volvemos a situar el corazón del problema en la concentración de la inversión bancaria en "ladrillo y cemento".

En cuanto a la capacidad explicativa del modelo estimado, la Tabla 5 informa de las tasas de clasificación correcta tomando distintas referencias. Obviamente, por contraposición, indica los errores de tipo I ("falsos negativos") y de tipo II ("falsos positivos"). Y, en definitiva, recoge la sensibilidad (porcentaje de verdaderos positivos) y especificidad (porcentaje de verdaderos negativos) de las clasificaciones.

En esta Tabla 5 se observa que la función discriminante estimada clasifica correctamente el 87,9 por ciento del conjunto de casos que componen la muestra de estimación. Es un porcentaje elevado, si tenemos en cuenta que el porcentaje total de clasificación correcta en una asignación puramente aleatoria a uno y otro grupo sería del 61,2 por ciento ${ }^{6}$. Para el grupo 0 (entidades sanas), el modelo clasifica correctamente el 92,1 por ciento, mientras que para el grupo 1 (entidades problemáticas) el porcentaje de acierto es del 76,0 por ciento. La proporción de instituciones clasificadas como sanas siendo realmente entidades con dificultades financieras ("falsos negativos" o error de tipo I) fue del 24,0 por ciento; y la proporción de sanas clasificadas como fracasadas ("falsos positivos" o error de tipo II) fue del 7,9 por ciento, siempre refiriéndonos al caso de la propia muestra de estimación.

Además, para comprobar la capacidad predictiva del modelo se realizó una validación cruzada (cross validation) en la forma denominada jackknife, en la cual la clasificación de cada caso se realiza después de dejarlo fuera del cálculo de la función discriminante. El resultado de la clasificación siguiendo esta es-

\footnotetext{
${ }^{6}$ Dado por: $\left[\left[\mathrm{n}^{\mathrm{o}} \operatorname{sanas} *\left(\mathrm{n}^{\mathrm{o}} \operatorname{sanas} / \mathrm{n}^{\circ} \text { total }\right)\right]+\left[\mathrm{n}^{\mathrm{o}} \text { fracasadas } *\left(\mathrm{n}^{\circ} \text { fracasadas } / \mathrm{n}^{\circ} \text { total }\right)\right] / \mathrm{n}^{\circ} \text { total }\right]^{*} 100$.
} 
trategia es similar al de la clasificación original; más concretamente, en términos globales clasifica de manera correcta el $86,8 \%$ de los casos.

Tabla 5

Clasificaciones con la función discriminante estimada

\begin{tabular}{|c|c|c|c|c|c|}
\hline & & \multirow{2}{*}{ Grupo } & \multicolumn{2}{|c|}{$\begin{array}{l}\text { Grupo de pertenencia } \\
\text { pronosticado }\end{array}$} & \multirow[t]{2}{*}{ Total } \\
\hline & & & 0 & 1 & \\
\hline \multirow{4}{*}{$\begin{array}{l}\text { Muestra de } \\
\text { estimación }\end{array}$} & \multirow{2}{*}{ Recuento } & 0 & 129 & 11 & 140 \\
\hline & & 1 & 12 & 38 & 50 \\
\hline & \multirow{2}{*}{$\%$} & 0 & 92,1 & 7,9 & 100,0 \\
\hline & & 1 & 24,0 & 76,0 & 100,0 \\
\hline \multirow{4}{*}{$\begin{array}{c}\text { Muestra de } \\
\text { validación }\end{array}$} & \multirow{2}{*}{ Recuento } & 0 & 118 & 13 & 131 \\
\hline & & 1 & 9 & 30 & 39 \\
\hline & \multirow{2}{*}{$\%$} & 0 & 90,1 & 9,9 & 100,0 \\
\hline & & 1 & 23,1 & 76,9 & 100,0 \\
\hline
\end{tabular}

Fuente: Elaboración propia.

Respecto a la muestra de validación, el modelo discriminante estimado clasifica correctamente el 87,1 por ciento de todas las entidades que la constituyen. El error de tipo II fue ahora del 9,9\%, situándose en el 23,1 por ciento el error de tipo I, siempre con las mismas probabilidades a priori y punto de corte discriminante que se utilizaron para el caso de las muestra de estimación y que más arriba se apuntaron.

Parece que la similitud de resultados de clasificación para la muestra de validación y la muestra de estimación, junto a los de la citada validación cruzada, verifican la fiabilidad de la función estimada. Además, debe recordarse que, al menos en lo que se refiere al fracaso de las entidades de depósito, seguramente ha de valorarse de muy distinto modo el error en una dirección o en otra: tendrá mucho más coste un error de tipo I que de tipo II. Si interesa considerar esto, habrá de tomarse como referencia que el coste total de los errores sea lo menor posible. Y, en ese contexto, las probabilidades a priori van en sentido contrario a los costes: por lo general, la probabilidad de fracasar es muy inferior a la probabilidad de mantener la normalidad, pero el coste de una insolvencia bancaria es elevado y compensa -por así decir- su baja probabilidad; en cambio, prever como fracasada una entidad realmente sana tiene un coste menor (Sanchís Arellano et al., 2003; Johnson y Wichern, 2007, cap. 11).

De esto se deduce que hay razones para trabajar con un punto de corte discriminante más elevado, en concreto aumentando la probabilidad a priori de dificultades financieras y reduciendo, consiguientemente, su probabilidad complementaria. Si, por ejemplo, se utilizan como probabilidades a priori 0,5 y 0,5 , se clasifican correctamente el $87,9 \%$ de los casos que componen la muestra de estimación, mismo porcentaje de acierto que considerando probabilidades pre- 
vias calculadas según tamaños de grupos. Sin embargo, atendiendo a cada grupo por separado, con las nuevas probabilidades a priori el modelo clasifica correctamente el $84,3 \%$ de las entidades sanas, mientras que para el grupo de entidades problemáticas el porcentaje de acierto es del 98,0\%. El error de tipo I (el más costoso), que se comete al asignar de sana a una entidad con problemas, es del 2,0\%. El error de tipo II, derivado de clasificar a entidades sanas como problemáticas, es del $15,7 \%$. Con respecto a la cross validation y la muestra de validación, en ambos casos, claramente, también se reduce el error de tipo I.

\section{CONCLUSIONES}

A lo largo del presente estudio, se ha tratado de presentar un modelo de clasificación de entidades bancarias a partir de la técnica del análisis discriminante lineal multivariante, precedido de un breve recorrido sobre la evolución de la reciente crisis bancaria en España.

Desde el año 2008 se han ido sucediendo en nuestro país toda clase de medidas con el fin de dotar de mayor solidez y transparencia al sistema financiero español. Entre los hitos más notables, cabe destacar los saneamientos en el sector, por un importe cercano a los 200.000 millones de euros, monto que equivale aproximadamente al 20 por ciento del PIB español. Además, los diferentes procesos de integración y/o "bancarización" -conversión en bancoshan supuesto la práctica desaparición de las tradicionales cajas de ahorros. Quedarán como únicas supervivientes las dos cajas más pequeñas, Caixa Ontinyent y Pollença. Como resultado de todos estos movimientos, se inicia el año 2014 con una más que notable reducción de entidades, pasando, en poco más de un lustro, de contar con 192 instituciones de depósito -entre cajas de ahorros, bancos y cooperativas de crédito- a 123 entidades, según datos de diciembre 2013.

En relación con el modelo estadístico multivariante estimado en el presente estudio, proporciona valiosa información sobre la situación que han atravesado diferentes entidades bancarias españolas. Los ratios financieros finalmente seleccionados e incluidos en dicho modelo no manifiestan multicolinealidad entre ellos, muestran altos niveles de tolerancia en la función discriminante y resultan significativos como variables diferenciadoras de los dos grupos, entidades sanas e instituciones con dificultades financieras.

De las cuatro variables explicativas incluidas en el modelo finalmente estimado, tres presentan signo positivo y una lo tiene negativo. Así, se ha comprobado que la probabilidad de que una entidad se haya visto inmersa en una circunstancia problemática durante los pasados años guarda una relación directa con:

a) Una variable de control expresión del tamaño de la institución -el logaritmo neperiano del total activo-, lo que da a entender que, por lo general, 
las situaciones de vulnerabilidad se encontraban en gran medida en organizaciones de considerable tamaño, sobre todo cajas de ahorros. La inmensa mayoría de los pequeños bancos comerciales y de las cooperativas de crédito se han mostrado relativamente sólidos durante los años de la Gran Recesión, lo mismo que los más grandes e internacionales grupos bancarios españoles.

b) Un ratio sobre la estructura del activo, en concreto referente al peso del activo material respecto al total activo. Esto penalizó en general a aquellas entidades que concentraban mayores activos inmobiliarios, además del caso específico de las cajas de ahorros y cooperativas de crédito, dado el inmovilizado material afecto a su Obra Social.

c) La tasa de crecimiento de las inversiones inmobiliarias realizadas. Resultado previsible, en el sentido de que fueron las entidades que más se han ido implicando en el sector inmobiliario las que han visto incrementarse sus posibilidades de encontrarse en situaciones de riesgo grave.

Por el otro lado, como variable en sentido contrario, es decir, que ha contribuido a eludir las dificultades financieras y a fortalecer la solidez de la entidad, nos encontramos con la tasa de crecimiento anual de los fondos propios. Recoge principalmente las variaciones en la tasa de incremento de los resultados del ejercicio y, en último término, de las reservas patrimoniales. Las instituciones de depósito que más cuidaron sus recursos propios parecen haber tenido menores problemas a la hora de acometer las recapitalizaciones.

Desde un punto de vista técnico los resultados estadísticos parecen adecuados, a la vista de su robustez y de la consistencia de los modelos estimados, máxime dentro del contexto de incertidumbre que ha caracterizado en muchos momentos al proceso de restructuración: sucesión de diversas leyes y otras normas, existencia de presiones políticas, malas prácticas de actuación en el negocio, etc.

No obstante, debe tenerse en cuenta que los costes de incurrir en un error en una o en otra dirección generalmente no van a ser los mismos. Por ejemplo, si clasificamos a una entidad prediciendo que experimentará dificultades financieras en un futuro y esta contingencia no tiene lugar (error de tipo II), el coste no iría más allá de los gastos de supervisión y pérdida de confianza en la institución. En cambio, si el error es de tipo I, es decir, predecimos que la entidad no tendrá problemas en el año posterior pero ocurre lo contrario, los costes de la reestructuración bancaria en los que se incurriría pueden ser muy elevados, tal y como se está viendo estos últimos años en España. Si la situación difícil de una organización se predice por adelantado, estos costes podrían reducirse.

Para poner término a este apartado de conclusiones, han de mencionarse las posibles debilidades de estos resultados empíricos alcanzados, así como futuras líneas de la investigación. El intervalo de tiempo considerado entre la señal y el 
fallo de la entidad no va más allá de un año contable, por lo que estos indicadores no podrían haber sido utilizados por los supervisores para tomar medidas de política preventiva a largo plazo. Además, pese a ser unos resultados satisfactorios, no se debe excluir la posibilidad de que otras variables no recogidas en esta investigación consigan aportar mayor capacidad clasificatoria. Por otra parte, en futuras investigaciones sería recomendable tener más presente la lógica primacía de los errores de tipo I respecto a los de tipo II, dada la mayor importancia que tienen los primeros sobre los segundos. Y sería posible enriquecer los resultados obtenidos mediante el uso, y posterior comparación, de modelos y técnicas de clasificación alternativas, como pueden ser los modelos logit o probit.

\section{REFERENCIAS BIBLIOGRÁFICAS}

AHUMADA, A. y BUDNEVICH, C. (1999). "Indicadores Financieros y Clasificación de los Bancos: Un análisis estadístico multivariado", Banco Central de Chile, Gerencia de Análisis Financiero, División de Estudios, Santiago de Chile. Disponible en libre acceso en: http://www.cemla.org/old/pdf/red/CH_ahumada_budnevich.pdf. [Último acceso: Agosto de 2013].

ALTMAN, E.I. (1968). "Financial ratios, discriminant analysis and the prediction of corporate Bankruptcy", Journal of Finance, 23(4), pp. 589-609.

ANDRÉS SUÁREZ, J. de (2001). "Aproximación empírica a la distribución estadística de los ratios contables", Revista de Contabilidad, 4(7), pp. 101-127.

ANDRÉS SUÁREZ, J. de (2005). "El pronóstico de la insolvencia empresarial mediante técnicas de inteligencia artificial: algunas propuestas innovadoras", Cuadernos aragoneses de economía, 15(2), pp. 275-300.

ASOCIACIÓN ESPAÑOLA DE BANCA (2007-2013). Anuarios Estadísticos. Madrid. http://www.aebanca.es. [Último acceso: Febrero de 2014].

BANCO DE ESPAÑA (2008-2011). Informe Anual. Madrid. Consultado el 15 de marzo de 2013, en: http://www.bde.es. [Último acceso: Diciembre de 2013].

BANCO DE ESPAÑA (2011). "El Banco de España comunica a 12 entidades que deben aumentar su capital para cumplir con el Real Decreto-ley". http://www.bde.es. [Último acceso: Diciembre de 2013].

BANCO DE ESPAÑA (2012a). Reforma del sector bancario español: medidas para reforzar la estabilidad financiera. Madrid. http://www.bde.es. [Último acceso: Diciembre de 2013].

BANCO DE ESPAÑA (2012b). Sareb completa el 100\% de su capital inicial, con mayoría de accionistas privados y con participación extranjera. Madrid. http://www.bde.es. [Último acceso: Marzo de 2014].

CLIMENT, S. (2013). "La reestructuración del sistema bancario español tras la crisis y la solvencia de las entidades financieras: consecuencias para las cajas de ahorros", Revista de Contabilidad-Spanish Accounting Review. http://dx.doi.org/10.1016/ j.rcsar.2013.07.003. [Último acceso: Septiembre de 2013]. 
CONFEDERACIÓN ESPAÑOLA DE CAJAS DE AHORROS (2007-2013). Anuarios Estadísticos. Madrid. http://www.ceca.es. [Último acceso: Diciembre de 2013].

CRESPO, J.Y. (2011). "CAMEL vs. discriminante un análisis de riesgo al sistema financiero venezolano”, Ecos de Economía, 15(33), pp. 25-47.

DEMYANYK, Y. y HASAN, I. (2009). "Financial crises and bank failures: a review of prediction methods", Discussion Papers, Bank of Finland, Helsinki.

DOUMPOS, M. y ZOPOUNIDIS, C. (2002). "Multicriteria decision aid classification methods", Kluwer Academic Publishers, Dordrecht.

GALBRAITH, J.K. (1991). Breve historia de la euforia financiera. Barcelona: Ariel.

GUTIÉRREZ, C. y ABAD, J. (2013). “¿Permitían los estados financieros predecir los resultados de los tests de estrés de la banca española? Una aplicación del modelo logit", Revista de Contabilidad-Spanish Accounting Review. http://dx.doi.org/ 10.1016/j.rcsar. 2013.08.004. [Último acceso: Noviembre de 2013].

HUTCHISON, M. y McDILL, K. (1999). "Are all banking crises alike? The Japanese experience in international comparison". NBER Working Paper 7253, Cambridge, Massachusetts. http://www.nber.org/papers/w7253.pdf. [Último acceso: Septiembre de 2013].

JOHNSON, R.A. y WICHERN, D.W. (2007). Applied multivariate statistical analysis. Upper Saddle River (NJ): Pearson Prentice Hall.

JORDAN, D. J., RICE, D., SANCHEZ, J., WALKER, C. y WORT, D. H. (2010). "Predicting Bank Failures: Evidence from 2007 to 2010", SSRN Working Paper, no 1652924, Nueva York. http://ssrn.com/abstract=1652924. [Último acceso: Septiembre de 2013].

KLECKA, W.R. (1980). Discriminant analysis. Thousand Oaks (CA): Sage Publications.

KOLARI, J. y ZARDKOOHI, A. (1987). Bank costs, structure, and performance. Lexington (MA): Lexington Books.

LAFFARGA, J., MARTÍN, J. L. y VÁZQUEZ, M. J. (1987). "Predicción de la crisis bancaria en España. Comparación entre el análisis logit y el análisis discriminante", Cuadernos de Investigación Contable, 1(1), pp. 103-111.

MARTIN, D. (1977). "Early warning of bank failure: a logit regression approach", Journal of Banking and Finance, 1, pp. 249-276.

MARTíNEZ, C., SANZ, F. y DE LA CRUZ, M. (1989). "Selección y explotación de los Sistemas de Alarma y Prevención de quiebra", Investigaciones Económicas, 13(3), pp. 465-484.

MEYER, P. y PIFER, H. (1970). "Prediction of Bank Failures", Journal of Finance, 24(3), pp. 853-868.

MUHAMMAD, M. (2012). "Predicting Bank Distress in Nigerian Banking Industry: A New Discriminant Analysis Model”. http://www.academia.edu. [Último acceso: Febrero de 2014].

OHLSON, J. (1980). "Financial ratio and the probabilistic prediction of bankruptcy", Journal of Accounting Research, 18(1), pp. 109-131.

PINA, V. (1989). "La información contable en la predicción de la crisis bancaria 19771985", Revista española de financiación y contabilidad, 19(58), pp. 309-338.

POHAR, M.; BLAS, M. y TURK, S. (2004). "Comparison of logistic regression and linear discriminant analysis: a simulation study”, Metodološki Zvezki, 1(1), pp. 143-161. 
RALLO, J.R. (2008). "El crédito bancario a la construcción en España (1993-2007)", Informe del Observatorio de Coyuntura Económica, Instituto Juan de Mariana. Madrid. http://www.juandemariana.org/estudio/2167/2/credito/bancario/construccion/espana/. [Último acceso: Abril de 2014].

RODRÍGUEZ FERNÁNDEZ, J.M. (1989). "The crisis in Spanish private banks: a logit analysis", Finance, 10(1), pp. 69-88.

RODRÍGUEZ FERNÁNDEZ, J.M. (2012). "Las cajas de ahorro españolas: el final de la escapada". En Alonso, L.E. y Fernández Rodríguez, C.J. (eds.): La financiarización de las relaciones laborales: una perspectiva internacional (pp. 280-297). Madrid: Catarata/FUHEM Ecosocial.

ROSE, P. y KOLARI, J. (1985). "Early warning systems as a monitoring device for bank condition", Quarterly Journal of Business and Economics, 24(1), pp. 43-60.

SAJTER, D. (2005). "Early prediction of bank failures in the Republic of Croatia", Tesis doctoral, Universidad de Osijek, Croatia. http://ssrn.com/abstract=963966. [Último acceso: Septiembre de 2013].

SAGARRA, M.; MAR MOLINERO, C. y GARCÍA CESTONA, M. (2011). "Spanish savings banks in the credit crunch: could distress have been predicted before the crisis? A multivariate statistical analysis", Fundación de las Cajas de Ahorros, Documento de trabajo $n^{\circ} 667 / 2011$.

SANCHÍS ARELLANO, A.; GIL, J.A. y HERAS MARTíNEZ, A. (2003). ). "El análisis discriminante en la prevision de la insolvencia en las empresas de seguro de no vida", Revista Española de Financiación y Contabilidad, 32(116), pp. 183-233.

SCAPENS, R.W.; RYAN R.J. y FLECHER L. (1981). "Explaining corporate failure: a catastrophe theory approach", Journal of Business Finance and Accounting, 8(1), pp. 1-26.

SERRA RAMONEDA, A. (2011). Los errores de las cajas: adiós al modelo de cajas de ahorros. Barcelona: Ediciones Invisibles.

SERRANO, C. y MARTÍN, B. (1993). "Predicción de la quiebra bancaria mediante el empleo de redes neuronales artificiales", Revista española de financiación y contabilidad, 23(74), pp. 153-176.

SINKEY, Jr., J. (1975). "A multivariate statistical analysis of the characteristics of problem banks", Journal of Finance, 30(1), pp. 21-36.

TASCÓN FERNÁNDEZ, M.T. y CASTAÑO GUTIÉRREZ, F.J. (2012). "Variables y modelos para la identificación y predicción del fracaso empresarial: revisión de la investigación empírica reciente", Revista de Contabilidad, 15(1), pp. 7-58.

UNIÓN NACIONAL DE COOPERATIVAS DE CRÉDITO (2007-2013). Anuarios Estadísticos, Madrid. http://www.unacc.com. [Último acceso: Abril de 2014]. 
